\title{
MECANISMOS DE DESGASTE DERIVADOS DE ADITIVOS CERÂMICOS EM LUBRIFICANTES FUEL ECONOMY
}

\author{
Marcos B.Garcia ${ }^{\mathrm{i}}$, Carlos Mussato ${ }^{\mathrm{ii}} \&$ Marco Colosio ${ }^{\mathrm{iii}}$ \\ ${ }^{\mathrm{i}}$ Energy Plus Treinamentos \& Consultorias, UFABC

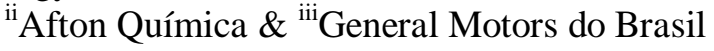

E-mails: marcos@clickenergy.com.br, carlos.mussato@gmail.com, marco.colosio@gm.com

\section{RESUMO}

Os fatores chaves que influenciam na evolução dos óleos de motores e tecnologias de aditivos são a economia de combustível, conservação ambiental, extensão dos intervalos de troca e a durabilidade dos catalizadores.

O aumento da relação carga-lubrificante nos veículos automotores tem causado efeitos adversos em relação ao atrito e desgaste dos componentes e a regulamentação dos níveis de emissões. Neste artigo foram estudados os efeitos de pequenas adições de partículas coloidais de $\mathrm{ZnO}$ e $\mathrm{Al}_{2} \mathrm{O}_{3}$ separadamente em óleo básico mineral parafínico visando substituir o tradicional aditivo organometálico ZDDP.

Os ensaios foram realizados em tribômetro Four Ball (ASTM D4172) com três níveis de carregamento, e as características de desgaste das esferas de aço (AISI 52100) assim como a incorporação de partículas (tribofilme) na região de contato foram analisadas por microscopia óptica e eletrônica de varredura (MEV/EDS).

Ao contrário do comportamento tribológico com lubrificante $\mathrm{ZnO}$, as partículas de $\mathrm{Al}_{2} \mathrm{O}_{3}$ não resultaram em grandes oscilações ao longo do ciclo de ensaio, demonstrando que talvez não tenha ocorrido alteração morfológica das partículas. As partículas disponíveis no lubrificante entram mais facilmente na região de contato beneficiando as características tribológicas para diferentes regimes de lubrificação.

Considerando o incremento de cargas, os mecanismos de desgaste mostraram que a adição de ZDDP inicialmente causou desgaste corrosivo, seguindo por abrasão e deformação plástica com a exposição de carbonetos; enquanto que a adição de partículas de $\mathrm{ZnO}$ causou desgaste abrasivo atenuado por um polimento superficial com alguma remoção de carbonetos e por fim uma intensa deformação plástica; $\mathrm{o} \mathrm{Al}_{2} \mathrm{O}_{3}$ causou desgaste abrasivo tênue com pouca remoção de carbonetos e por fim uma intensa deformação com pequena delaminação superficial.

\section{INTRODUÇÃO}

De acordo com SONG (2012), um terço da energia no mundo será consumido devido ao atrito, assim como a maioria das falhas dos elementos de máquina ocorrerá pelo excesso de desgaste. A escassez de petróleo e a exigência do mercado global para regulamentação dos níveis de emissões, assim como a durabilidade dos veículos automotores, estão voltadas para os efeitos adversos que requerem a redução do atrito ${ }^{1}$.

As principais causas de desgaste no motor são devido ao contato metal-metal (lubrificação limítrofe), na presença de partículas abrasivas e pelo ataque de ácidos corrosivos 2 . 
Os motores de combustão interna são termodinamicamente muito ineficientes, e ainda são susceptíveis a significativas perdas mecânicas pelo atrito. Aproximadamente $12,6 \%$ da energia avaliada encontram-se no contato dos pneus com o pavimento, enquanto que o motor contribui com $62,4 \%$ da perda mecânica dissipada, principalmente por atrito ${ }^{3}$.

Os fatores chaves que influenciam na evolução dos óleos de motores e tecnologias de aditivos são a economia de combustível, conservação ambiental e extensão dos intervalos de troca. Durante muito tempo tem sido reconhecido que a suspensão de partículas sólidas em líquido proporciona vantagens para indústria de fluidos, onde se inclui produtos para transferência de calor, fluidos magnéticos e lubrificantes ${ }^{4}$.

Alguns produtos da decomposição do aditivo diaquil diotifosfato de zinco (ZDDP) aceleram o desgaste corrosivo, em função de uma reação da superfície com o excesso de enxofre oriundos dos subprodutos. Como consequência, os óleos usados causam um aumento do desgaste, mas por outro lado, pode ocorrer a diminuição do atrito ${ }^{5}$.

As recentes exigências para prolongar a vida dos catalisadores de gases de escape estão considerando a redução nos níveis de enxofre e fósforo contidos no óleo do motor, pois estes elementos são considerados danosos ao catalisador. No entanto, a redução nas concentrações de ZDDP deve ser providenciada em um futuro próximo.

Durante muito tempo tem sido reconhecido que a suspensão de partículas sólidas em líquido pode proporcionar vantagens para indústria de fluidos, onde se inclui produtos para transferência de calor, fluidos magnéticos e lubrificantes ${ }^{6}$.

As propriedades únicas relativas ao baixo peso, elevada dureza, estabilidade térmica e inércia química são os diferenciais das cerâmicas em relação a outros materiais de engenharia, e estão sendo considerada como o principal candidato para o uso em aplicações tribológicas ${ }^{7}$.

Para MARTIN (2008), outra forma de uso das nanopartículas é através de sua incorporação em revestimentos superficiais para melhorar as características tribológicas, mas que durante o processo de desgaste as nanoparticulas podem ser removidas do revestimento e conseqüentemente introduzidas ao lubrificante, como uma aditivação não espontânea ${ }^{8}$.

De acordo com a norma alemã DIN 50320, "a perda progressiva de material da superfície de contato em sólidos como resultado de ações mecânicas" é definida como desgaste. Os parâmetros que afetam o desgaste são carga, velocidade, temperatura, geometria da superficie de contato, condições do meio, aspecto triboquímico e material/tratamento superficial $^{9}$.

A acomodação dos componentes de sistemas complexos com inúmeras peças em movimento relativo pode apresentar diferentes taxas de degradação para cada componente ou subsistema, que estão simultaneamente relacionados com os processos de transição do desgaste (severo-moderado) que ocorrem entre as superfícies de contato ${ }^{10}$.

O desgaste por deslizamento pode ser classificado como moderado quando resulta de reações triboquímicas formando substâncias corrosivas (ou oxidativa) na superfície de contato, enquanto que o desgaste severo ocorre pela remoção da camada de óxido ou tribofilme propiciando o contato metal-metal, e pode englobar também todos os mecanismos oriundos da deformação plástica. Os mecanismos de deslizamento envolvem movimento de grande quantidade de discordâncias, que são responsáveis pela deformação plástica na superfície de contato. As discordâncias geradas são armazenadas no corpo e propagam-se com o carregamento ${ }^{11}$.

O movimento relativo também pode resultar no desgaste corrosivo com a degradação de uma camada superficial do material devido às reações advindas do meio. A formação de fragmentos, oriundas da oxidação/corrosão, pode provocar desgaste abrasivo (três corpos) na região de contato. A Figura 1 apresenta esquematicamente o comportamento típico da degradação para os diferentes mecanismos de desgaste ${ }^{9}$. 


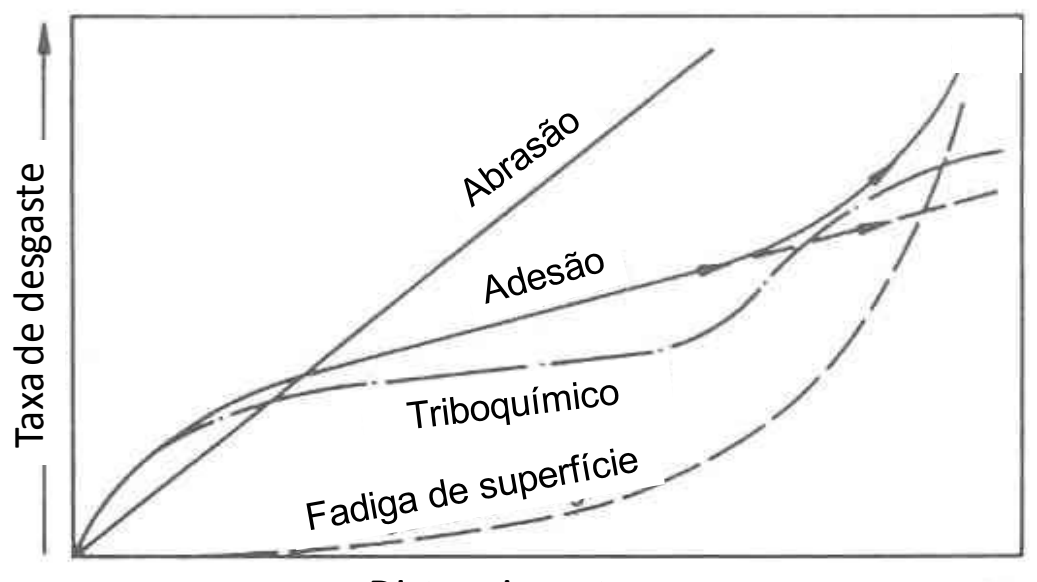

Distancia ou tempo

Figura 1 - Taxa de desgaste em função do tempo de operação ou distância de deslizamento e os mecanismos de desgaste dominante (ZUM GAHR, 1987).

O mecanismo de desgaste abrasivo ocorre de forma linear em relação a taxa de desgaste e distância de deslizamento. Enquanto que os mecanismos de adesão, fadiga de superficie e triboquimico podem influenciar a taxa de desgaste em diferentes periodos de deslizamento 9 .

As perdas por atrito em sistemas lubrificados são de aproximadamente $2 / 3$ para o regime hidrodinâmico e 1/3 para o misto, que envolve o elasto-hidrodinâmico e o boundary (limítrofe). Neste último, as condições do regime de lubrificação e os mecanismos de desgaste ocorrem em escala atômica, ainda pouco explorado e carente de estudos sobre as reações físico-químicas que ocorrem na superfície de contato ${ }^{12}$.

A Figura 2 representa a viscosidade efetiva em função da espessura do filme lubrificante $(\lambda)$. Quando a espessura tem dimensão molecular, a diminuição da espessura do filme lubrificante resulta no aumento da viscosidade e, também, na elasticidade do cisalhamento e no tempo de relaxamento do fluido ${ }^{13}$.



Figura 2 - Diagrama esquemático da relação de viscosidade e espessura do filme lubrificante (CHO, 1997).

A lubrificação em nanoescala (controle do atrito e adesão) requer moléculas de lubrificantes não voláteis, resistência à oxidação e a decomposição térmica, ter boa aderência e coesão, assim como capacidade de auto-reparação e regeneração. 
Foi observado por BATTEZ (2006) que as nanopartículas penetram no contato lubrificado EHD (elasto-hidrodinâmico) através de uma retenção mecânica em baixa velocidade; quando o diâmetro das partículas é maior que a espessura da película de lubrificante, elas cadenciam a espessura do filme. Além disso, o filme limítrofe formado pelas nanopartículas na região de contato é semelhante a um sólido, sendo incapaz de reparar a superfície sob altas velocidades, pois nesta condição a espessura do filme será menor que o diâmetro da partícula ${ }^{14}$.

\section{METODOLOGIA}

Os materiais utilizados na preparação dos lubrificantes coloidais foram óleo mineral parafínico (grupo II), tensoativo ácido oléico e as partículas cerâmicas de $\mathrm{ZnO}$ e $\mathrm{Al}_{2} \mathrm{O}_{3}$ obtidas das empresas Votorantim Metais (Brasil) e Taimei Metals (Japão), respectivamente.

\section{Óxido de Zinco (ZnO)}

É um óxido anfótero de estrutura hexagonal praticamente insolúvel em água e álcool, reage lentamente com os ácidos graxos de óleos produzindo carboxilatos tais como oleato ou estearato. A Figura 3 indica o tamanho de aglomerados de $\mathrm{ZnO}$ com 99,5\% de pureza, área de superfície de $4,2 \mathrm{~m}^{2} / \mathrm{g}$ e dureza de 4,6 Mohs.

\section{Óxido de Alumínio $\left(\mathrm{Al}_{2} \mathrm{O}_{3}\right)$}

Trata-se de um óxido anfótero de estrutura hexagonal comumente conhecido como alumina, ou coríndon, amplamente usado para a produção do metal alumínio, mas também é empregado como abrasivo devido à sua elevada dureza $(9 \mathrm{Mohs})$, e como material refratário pelo seu alto ponto de fusão. Além disso, sua baixa retenção de calor (isolante térmico) e baixo calor específico permitem que seja utilizado em operações de retifica e ferramentas de corte.

A Figura 3 também indica a distribuição de tamanho dos aglomerados de $\mathrm{Al}_{2} \mathrm{O}_{3}$ com $99,99 \%$ de pureza e área de superfície de $14,95 \mathrm{~m}^{2} / \mathrm{g}$.

A seguir à Figura 4 apresenta imagens de microscópio eletrônico de varredura (MEV) mostrando a morfologia das partículas primárias e a distribuição do tamanho de aglomerados das partículas de $\mathrm{ZnO}$ e $\mathrm{Al}_{2} \mathrm{O}_{3}$.

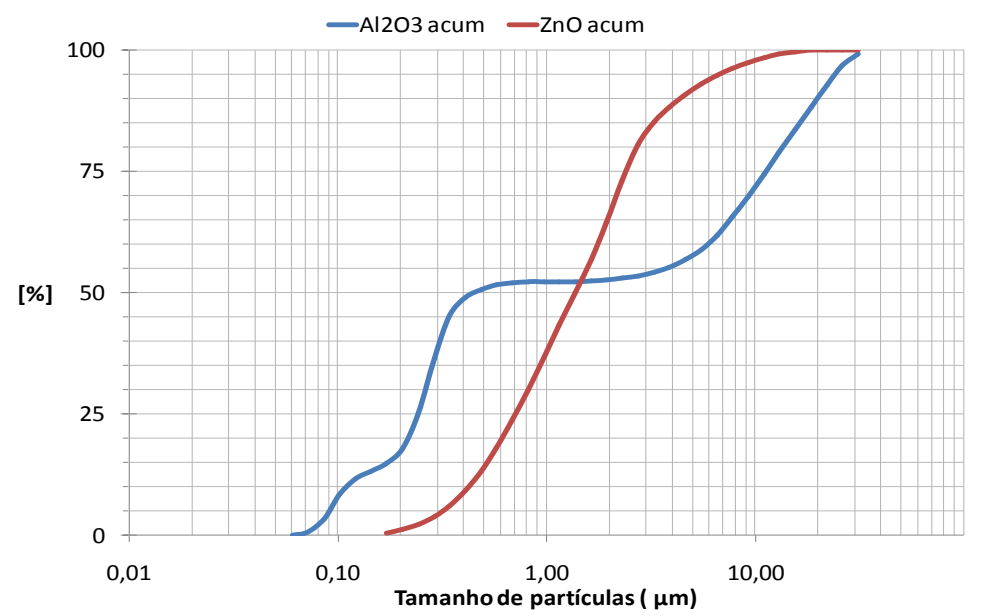

Figura 3 - Distribuição acumulada do tamanho de aglomerados dos pós de $\mathrm{ZnO}$ e $\mathrm{Al}_{2} \mathrm{O}_{3}$. 
As distribuições de tamanho dos aglomerados de partículas de ambos os pós cerâmicos mostraram que aproximadamente $45 \%$ eram menores ou iguais a $1 \mu \mathrm{m}$. O tamanho de aglomerados da alumina apresentou uma variação entre 0,07 e $37 \mu \mathrm{m}$, sendo que a metade estava entre 0,5 e $2,3 \mu \mathrm{m}$, enquanto que o tamanho do óxido de zinco variou entre 0,17 e 18,5 $\mu \mathrm{m}$, sendo a maior porção $(\sim 10 \%)$ com $2,31 \mu \mathrm{m}$, e para as partículas de $\mathrm{Al}_{2} \mathrm{O}_{3}$ foi bimodal com máximas de 0,11 e $0,29 \mu \mathrm{m}$. Notou-se que apesar das partículas primárias do $\mathrm{Al}_{2} \mathrm{O}_{3}$ terem sido menores (50 a $250 \mathrm{~nm}$ ), com maior área de superfície, parte dos aglomerados era maior (até $37 \mu \mathrm{m}$ ) do que os aglomerados de $\mathrm{ZnO}$ (até 18,5 $\mu \mathrm{m}$ ), o qual apresentou partículas primárias na ordem de 100 a $500 \mathrm{~nm}$.

Após a preparação, os lubrificantes coloidais apresentaram boa estabilidade, considerando o baixo efeito do ácido oléico na modificação da superfície das partículas.
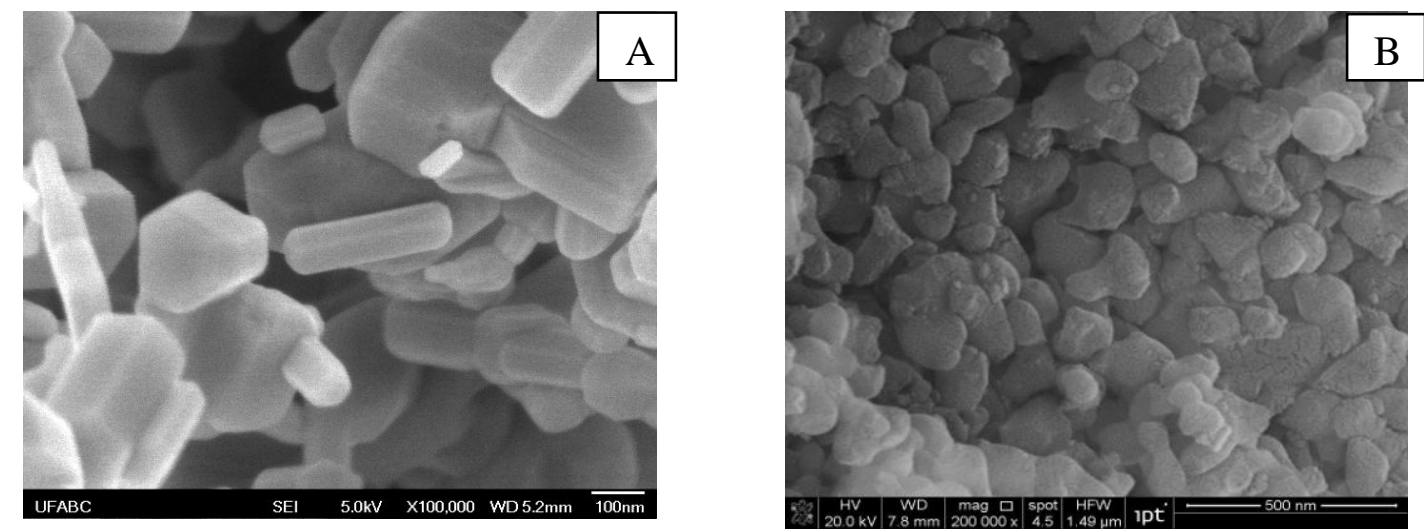

Figura 4 - Imagem de elétrons secundários (MEV) das partículas de óxido de zinco (A) e óxido de alumínio (B).

A preparação dos lubrificantes com adição de $0,5 \%$ de partículas cerâmicas $(\mathrm{ZnO}$ e $\mathrm{Al}_{2} \mathrm{O}_{3}$ ) modificadas como aditivo em óleo básico, foram baseadas nos métodos de DALTIN ${ }^{15}$, e adequados para este estudo.

\section{Diaquil Ditiofosfato de Zinco (ZDDP)}

Por muitos anos, o ZDDP patenteado em 1944 tem sido o aditivo multifuncional que apresenta características antidesgaste e oxidantes mais comumente usadas, e a sua concentração nos lubrificantes automotivos são de aproximadamente $0,5 \% \mathrm{em}^{\text {massa }}{ }^{[6][8]}$. $\mathrm{O}$ ZDDP é um aditivo produzido em duas etapas. Primeiro trata-se o pentassulfureto de fósforo com álcoois apropriados para se obter o ácido ditiofosfórico, permitindo a lipofilicidade do zinco no produto final. O ditiofosfato resultante é então neutralizado pela adição de óxido de zinco.

\section{Tribometro Four Ball ASTM D4172 $2^{(16)}$}

A Figura 5 ilustra o aparato do tribômetro Four Ball, que tem sido amplamente utilizado em estudos da formação de tribofilmes durante a lubrificação limítrofe e de extrema pressão, principalmente para a avaliação de lubrificantes de engrenagens, usinagem e outras aplicações de extrema pressão. A Figura 6 apresenta a microestrutura do material AISI 52100 das esferas empregadas no ensaio Four Ball, mostrando matriz de martensita revenida com dispersão de carbonetos ricos em cromo. 
Durante os ensaios tribológicos (temperatura de partida do lubrificante $75^{\circ} \mathrm{C}$, três réplicas para cada lubrificante coloidal com duração de ensaio de 1 hora e $1200 \mathrm{rpm}$ ) foram realizadas as medições da força de atrito a cada 50 segundos. Ao término foram determinados os diâmetros e as áreas da calota de desgaste das esferas através do analisador de imagem proveniente do microscópio óptico.

As cargas definidas para o ensaio comparativo foram de 147,392 e $588 \mathrm{~N}$, em intervalos de carregamento não sujeitos a desgaste adesivo. Nestas condições se buscou diferentes regimes de lubrificação deste tribosistema.

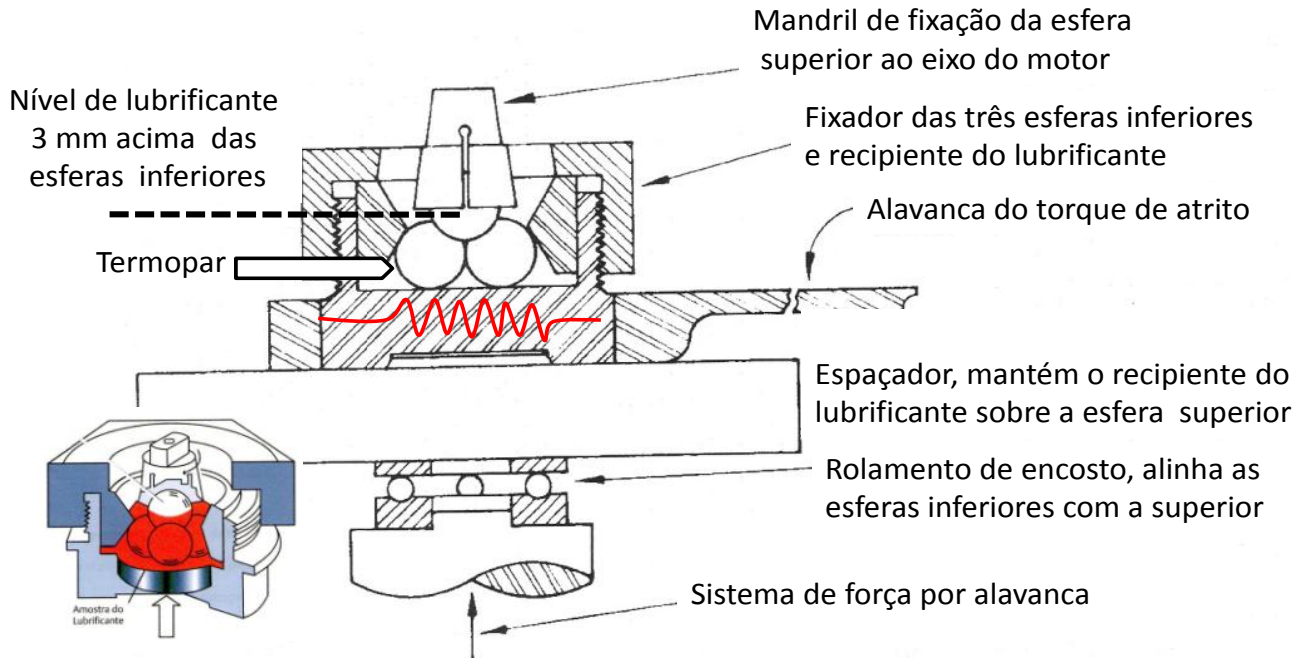

Figura 5 - Esquema de montagem do equipamento Four Ball e as condições de fixação das esferas e reservatório do lubrificante

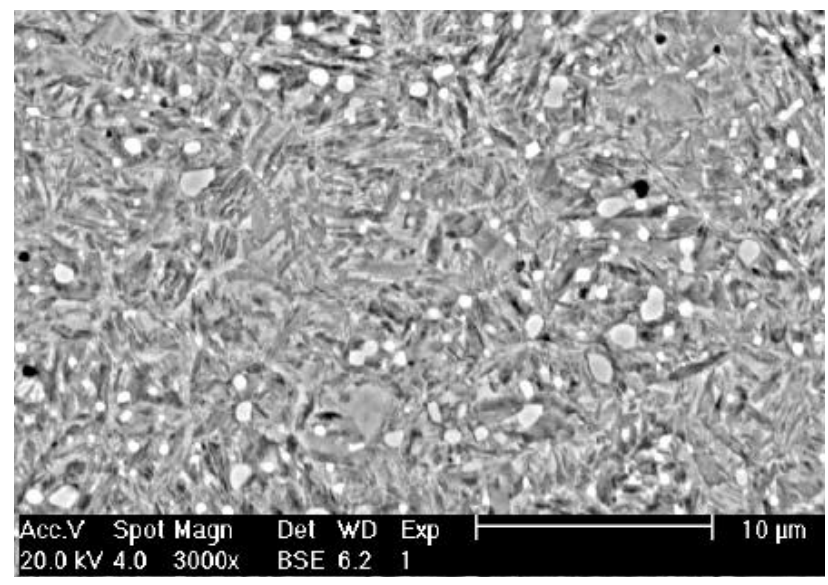

Figura 6 - Microestrutura do material da esfera (aço AISI 52100), ataque Nital 3\%. Imagem de elétrons retroespalhados (MEV), observa a presença de martensita e alguns carbonetos.

\section{Análise da Região de Contato das Esferas}

A quantificação do desgaste foi determinada pela medição dos diâmetros de desgaste, em função do tempo percorrido $(\mathrm{mm} / \mathrm{s})$. O efeito dos aditivos nas amostras dos lubrificantes foi determinado pela média dos menores diâmetros da calota de desgaste (scar wear) para as três esferas fixadas na parte inferior, como ilustrado pela Figura 7. 

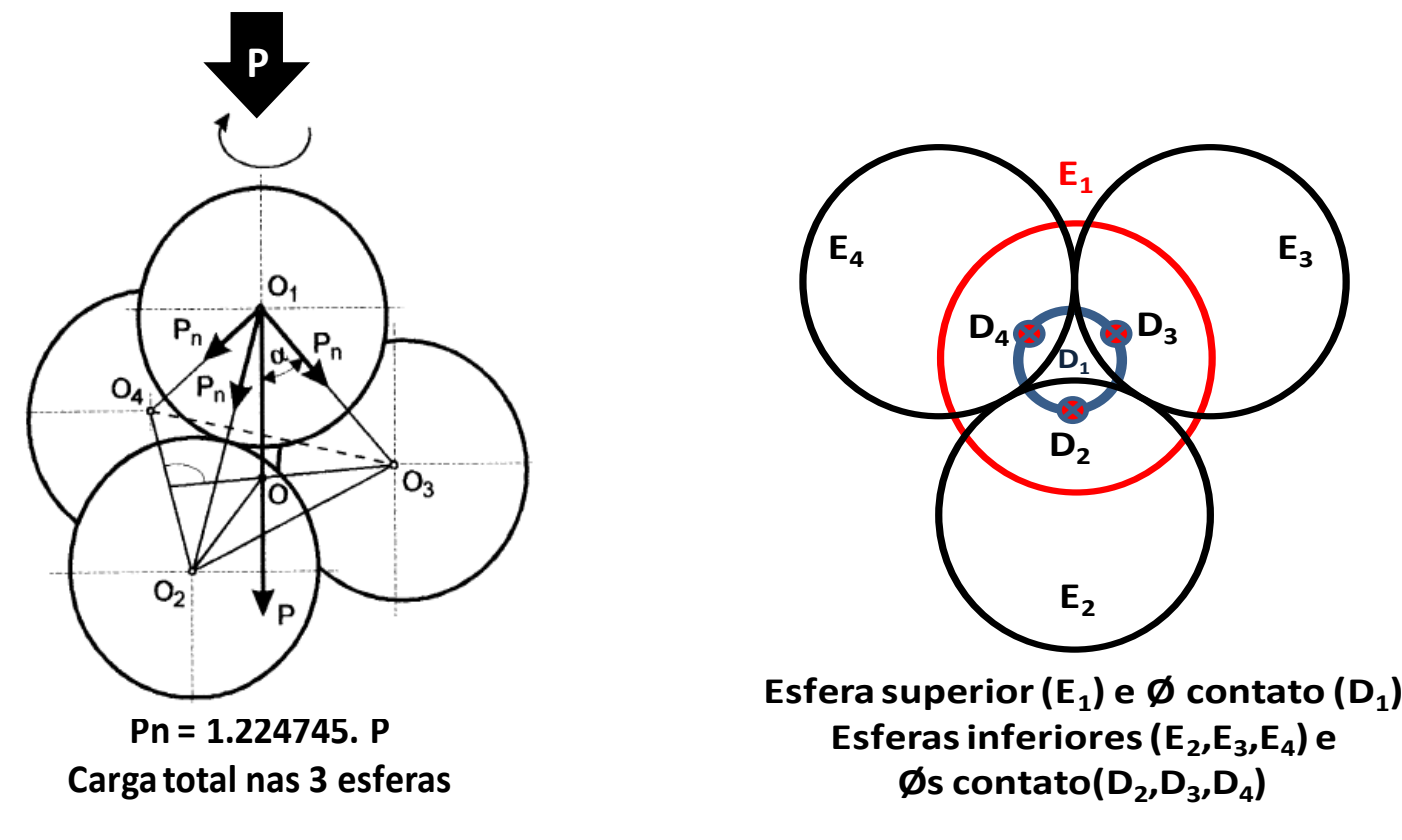

Figura 7 - Representação da disposição das esferas (superior e inferiores) e as respectivas cargas e regiões de contato (Dn) no Four Ball. A seta P indica a carga aplicada nas esferas.

\section{RESULTADOS E DISCUSSÕES}

A Figura 8 apresenta as fotomicrografias da região típica de desgaste das esferas inferiores (down balls) para todas as cargas avaliadas submetidas à carga de $392 \mathrm{~N}$. As setas indicam a direção de deslizamento do tribosistema Four Ball.


Figura 8 - Fotomicrografia da calota de desgaste após 1 hora de ensaio Four Ball com cargas intermédias de $392 \mathrm{~N}$ (a) $\mathrm{ZDDP}$, (b) $\mathrm{ZnO}$ e (c) $\mathrm{Al}_{2} \mathrm{O}_{3}$

Na Figura 8.a, o ZDDP na condição de carregamento com 147 N, observou-se nas esferas inferiores uma região de desgaste com coloração marron (claro e escuro) e pequenas porções cinza claro. Para carga intermédiária (392 N), notou-se uma colônia azulada, enquanto que para a maior carga $(588 \mathrm{~N})$ observaram-se regiões marron claro, e outra mais dispersa na cor cinza escura. Tomando-se como base a identificação de TONCK (1979) para 
adição de ZDDP, pode-se inferir que as regiões marrom estão associadas com formação de filme de $\mathrm{ZnO}$ enquanto as regiões azuladas com filme de $\mathrm{FeO}$.

Considerando a Figura 8.b coloração da superfície de desgaste, na carga de $147 \mathrm{~N}$ observaram-se regiões com coloração marrom intercaladas em menores proporções com regiões de cor cinza claro e azuladas. Para as cargas maiores, as áreas marrons diminuíram e as regiões cinza e azuladas aumentaram.

A Figura 8.c apresenta as fotomicrografias da região de desgaste das esferas inferiores com adição de partículas de $\mathrm{Al}_{2} \mathrm{O}_{3}$. Os aspectos ópticos das calotas apresentaram tonalidade mais clara do que os observados para adições de ZDDP e ZnO. Observaram-se formação de riscos em todas as cargas, como observado para adição de $\mathrm{ZnO}$.

\section{a) Características das Superfícies de Desgaste com ZDDP}

A Figura 10 apresenta imagens de MEV das superfícies das calotas de desgaste das esferas ensaiadas com diferentes cargas e lubrificante com ZDDP. Na carga de $147 \mathrm{~N}$, observou-se uma superfície com aspecto alveolar com cavidades da ordem de $1 \mu \mathrm{m}$ (Fig. 10.a), não apresentando característica de superfície deformada ou com sulcos de abrasão.

Aparentemente os alvéolos foram formados por um processo de corrosão considerando que os carbonetos de cromo presentes no aço AISI 52100 apresentaram tamanhos da ordem de $1 \mu \mathrm{m}$ (Fig.6), infere-se que ocorreu ataque químico na interface entre os carbonetos e a martensita da matriz, resultando em remoção das partículas da superfície e formação das cavidades. Assim, na carga de $147 \mathrm{~N}$, o ZDDP adsorvido quimicamente na superfície de contato parece ter induzido a ocorrência de um desgaste corrosivo. Já para carga intermediária de $392 \mathrm{~N}$, notou-se a presença de riscos intensos e relativamente profundos paralelos à direção de deslizamento (Fig. 4.16c) decorrente de um processo de desgaste abrasivo.

Também se observou em algumas regiões características sugerindo a formação localizada de tribofilmes possivelmente relacionados ao ZDDP (Fig.10.b). Para carga de 588 $\mathrm{N}$, foram observadas regiões com aspecto de tribofilme recobrindo parcialmente a superfície e regiões com indícios de corrosão moderada expondo partículas de carboneto de cromo na superfície (indicadas com setas na Fig.10.c), associados à deformação plástica moderada da superfície de contato.


Figura 10 - Imagens de elétrons secundários (MEV) da região típica de desgaste da esfera inferior após ensaio Four Ball com lubrificante com ZDDP em carga de:

(a) $147 \mathrm{~N}$; (b) $392 \mathrm{~N}$; (c) $588 \mathrm{~N}$.

\section{b) Características das Superfícies de Desgaste com ZNO}

A Figura 11 apresenta imagens de MEV das superfícies das calotas de desgaste ensaiadas em diferentes cargas com o lubrificante aditivado com $\mathrm{ZnO}$. Os aspectos superficiais foram similares nas calotas desgastadas em 147 e 392 N (Fig.11.a-b). 
Observaram-se aspectos de deformação plástica superficial formando pistas relativamente densas, paralelas à direção de deslizamento, intercaladas com regiões deformadas com a presença de cavidades irregulares da ordem de $1 \mu \mathrm{m}$, algumas alongadas na direção de deslizamento.

As formas destas cavidades sugeriram a ocorrência de processo de arrancamento (extração) e arraste de partículas de carboneto de cromo da esfera. A não ocorrência de corrosão e a indução de deformação plástica alisando a superfície, sem ocorrência de sulcamento profundo, podem ter sido as causas do melhor desempenho de desgaste observado com adição de $\mathrm{ZnO}$ nas cargas de 147 e $392 \mathrm{~N}$, em relação ao ZDDP e $\mathrm{Al}_{2} \mathrm{O}_{3}$.

Para condição de carga mais alta $(588 \mathrm{~N})$, observaram-se aspectos de deformação plástica e formação de sulcos paralelos à direção de deslizamento na superfície de contato (Fig.11.c).
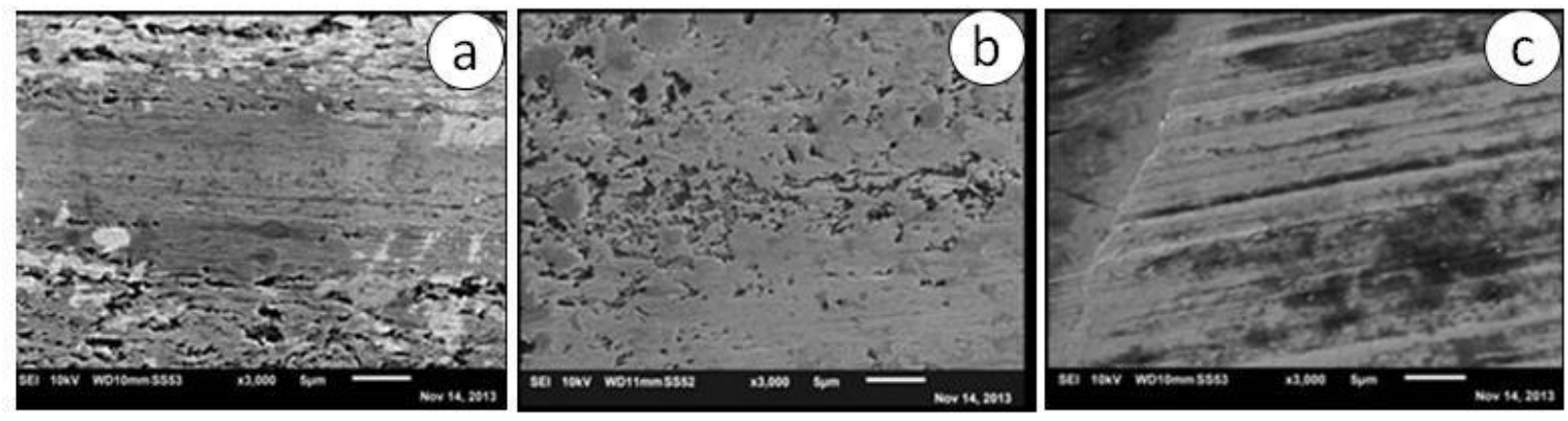

Figura 11 - Imagens de elétrons secundários (MEV) da região de desgaste da esfera inferior após ensaio Four Ball com lubrificante com $\mathrm{ZnO}$ em carga de:

(a) $147 \mathrm{~N}$; (b) $392 \mathrm{~N}$; (c) $588 \mathrm{~N}$.

\section{c) Características das Superfícies de Desgaste com $\mathrm{Al}_{2} \mathrm{O}_{3}$}

A Figura 12 apresenta as calotas de desgaste após ensaios Four Ball com adição de $\mathrm{Al}_{2} \mathrm{O}_{3}$, indicando um polimento da superfície relativamente melhor do que com adições de ZDDP e ZnO. Para carga de $147 \mathrm{~N}$, a superfície contém poucos riscos não profundos em meio a regiões com concentração de cavidades formadas aparentemente por arrancamento e arraste de carbonetos da esfera, similar ao observado para o $\mathrm{ZnO}$, mas em uma condição menos intensa (Fig.12.a). Em 392 N, a superfície apresentou ligeira abrasão com riscos alinhados na direção de deslizamento, mas com grandes áreas polidas e pouco arrancamento de carbonetos (Fig.12.c).

Estas características sugerem que ocorreu um processo de polimento superficial causado provavelmente pelas partículas duras e abrasivas de $\mathrm{Al}_{2} \mathrm{O}_{3}$, que são utilizadas comumente para este fim. O polimento da superfície é uma condição que favorece a ocorrência de lubrificação elastohidrodinâmica para que um filme fino de lubrificante atue entre as superfícies do corpo e contra-corpo e suporte a pressão aplicada. A formação de superfícies polidas parece explicar o comportamento estável do coeficiente de atrito com adição de $\mathrm{Al}_{2} \mathrm{O}_{3}$. No ensaio com carga de $588 \mathrm{~N}$, ocorreu intensa deformação seguida por delaminação superficial em algumas regiões (Fig.12.c). 

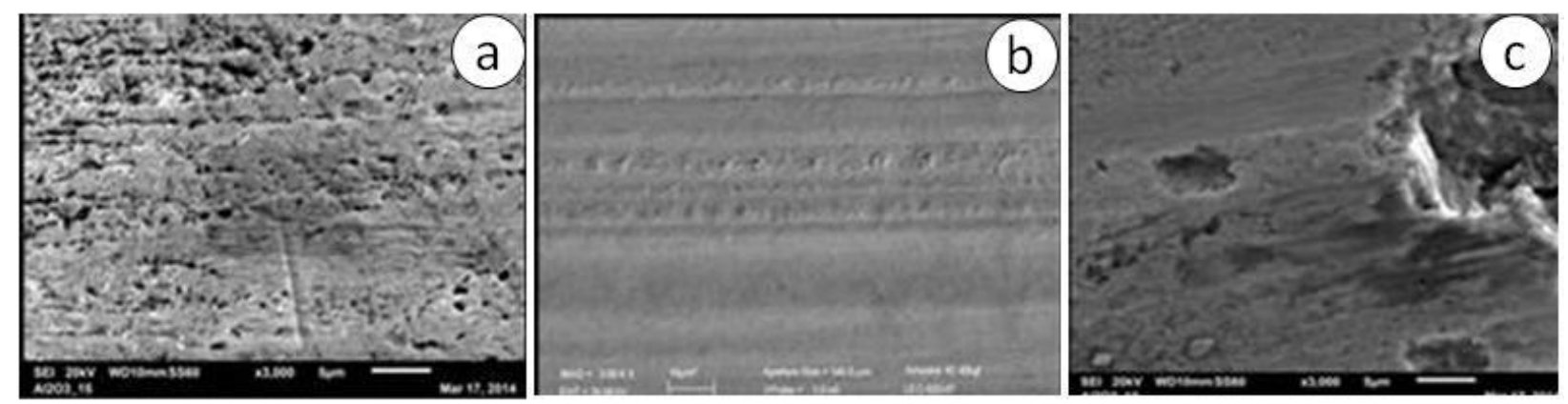

Figura 12 - Imagens de elétrons secundários (MEV) da região de desgaste da esfera inferior após ensaio Four Ball com lubrificante com $\mathrm{Al}_{2} \mathrm{O}_{3}$ em carga de:

(a) $147 \mathrm{~N}$; (b) $392 \mathrm{~N}$; (c) $588 \mathrm{~N}$.

Nas regiões de desgaste que utilizaram lubrificantes coloidais foi observada maior exposição de carbonetos (maior retenção de lubrificante) na superfície de contato das esferas (AISI 52100), provavelmente oriundo de um mecanismo de rolamento das partículas do lubrificante $\mathrm{ZnO}$ não incorporadas às superfícies de contato, enquanto que utilizando o aditivo $\mathrm{Al}_{2} \mathrm{O}_{3}$ prevaleceu o mecanismo de micro abrasão (polimento), possivelmente associado à incorporação de partículas na região de desgaste das esferas; tais mecanismos também são atribuídos aos nanolubrificantes (SONG, 2012).

As nanopartículas, assim como as partículas coloidais, apresentam importantes vantagens em relação a moléculas orgânicas, pois não necessitam de período de ativação (MARTIN, 2008), além de excelente estabilidade química e térmica que contribuem em aplicações em altas temperaturas. Vale destacar que pequenas quantidades de nanoparticulas disponíveis no lubrificante entram mais facilmente na região de contato beneficiando as propriedades tribológicas para diferentes condições de aplicações, contribuindo na vida útil dos lubrificantes modernos e consequentemente na melhoria da conservação de energia para os sistemas de transformação e de transportes.

\section{CONSIDERAÇÕES FINAIS}

- Quanto aos mecanismos de desgaste considerando as crescentes cargas: i) a adição de organometálico ZDDP inicialmente causou desgaste corrosivo, seguindo para o abrasivo e deformação plástica com a exposição de carbonetos nas cargas maiores de ensaio; ii) a adição de partículas de $\mathrm{ZnO}$ causou desgaste abrasivo atenuado por alisamento superficial com algumas remoções de carbonetos e por fim uma intensa deformação plástica; e iii) a adição de partículas de $\mathrm{Al}_{2} \mathrm{O}_{3}$ causou desgaste abrasivo fino com polimento superficial e pouco extração de carbonetos, em cargas baixa e moderada, e depois intensa deformação com pontos de delaminação em alta carga;

- As maiores áreas de tribofilmes, assim como a exposição de carbonetos oriundos da corrosão do material das esferas, foram mais evidentes com a utilização de ZDDP. Já a melhor dispersão de partículas na superfície de contato foi observada para o aditivo $\mathrm{Al}_{2} \mathrm{O}_{3}$;

- As maiores áreas de tribofilmes, assim como a exposição de carbonetos oriundos da corrosão do material das esferas, foram mais evidentes com a utilização de ZDDP. Enquanto a dispersão e/ou incrustação de partículas na superfície de contato foi muito

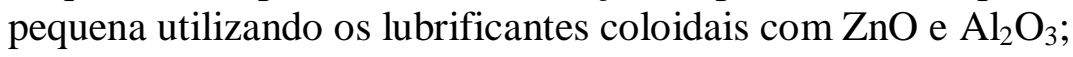




\section{REFERÊNCIAS}

1 SONG, X.; ZHENG, S.; ZHANG, J.; LI, W.; CHEN, Q.; CAO, B. Synthesis of monodispersed $\mathrm{ZnAl} 2 \mathrm{O} 4$ nanoparticles and their tribology properties as lubricant additives, Materials Research Bulletin 47 (2012) 4305-4310

2 KHORRAMIAN, B.A.; IYER, G.R.; KODALI, P.; NATARAJAN, P.; TUPIL, R. Review of antiwear additives for crankcase oils. Wear 169 (1993) 87-95.

3 HOLMBERG, K. Reliability aspects of tribology. Tribology International, v. 34, n. 12, p. 801-808, 2001.

4 HWANG, Y.; LEE, J.; LEE, L.; JEONG., Y.; CHEONG, S.; AHM, Y.; KIM, S.H. Production and dispension stability of nanoparticles in nanofluids. Powder technology 186 (2008) 145-153

5 MASUKO, M.; OHKIDO, T.; SUZUKI, A.; UENO, T. Fundamental Study of Changes in Friction and Wear Characteristics due to ZnDTP Deterioration in Simulating Engine Oil Degradation during Use, Transient Processes in Tribology, p.359-366, 2004

6 ÁVILA, R.N.A.; AZEVEDO, B.E.A.; SODRÉ, J.R. Influence of friction modifier additives on the tribology of lubricating oils. Proceedings... In: SOCIETY AMERICAN ENGINEERING, 2005, Brasil.

7 QURESHI, F.S.; WINER, W.O. On the Effects of Automotive Engine lubricants on the Friction and Wear Characteristics of Selected Ceramics under Sliding Conditions, U. S. Department of Energy,

Energy Conversion Technology Utilization Program (ECUT), p.471-476, 1991

8 MARTIN, J.M.; OHMAE, N. Nanolubricants. JohnWiley \& Sons, Ltd, 2008

9 LIN, Z.; SUN, J.; SHEN, W. Study of plowing and friction at the surface of plastic deformed metals. Tribology International, v. 35, p. 511-522, 2002.

10 NEVILle, A.; MORINA, A.; HAQUE, T.; VOONG, M. Compatibility between tribological surfaces and lubricant additives - slow friction and wear reduction can be controlled by surface/lube synergies. Tribology International, v. 40, p. 1680-1695, 2007

11 BRUSHAN, B. Nanotribology, nanomechanics and nanomaterials characterization. Philosophical Transactions of Royal Society, v. 366, p. 1351-1381, 2008.

12 BARTZ, W.J. Viscosity influence on friction conditions and fuel economy of automobiles.

Proceedings... Technishe Akademie Esslingen (1997) SAE 972858.

13 CHO, Y.K.; CAI, L.; GRANICK, S. Molecular tribology of lubrificants and additives. Tribology International, v.30, n. 12, p. 889-894, 1997.

14 BATTEZ, A.H.; GONZALEZ, R.; VIESCA, J.L.; FERNANDEZ, J.E.; DIAZ- FERNANDEZ, J.M.; MACHADO, A.; CHOU, R.; RIBA J. $\mathrm{CuO}, \mathrm{ZrO}_{2}$ and $\mathrm{ZnO}$ nanoparticles as antiwear additive in oil lubricants. Wear, v. 265, p. 422-428, 2008.BAYER, R.G. Mechanical wear prediction and prevention, Marcel Dekker, p.657, 1994

15 DALTIN, D. Tensoativos: química, propriedades e aplicações. São Paulo: Editora Blucher, 2011.

16 ASTM D4172-94 (2010), Standard test method for wear preventive characteristics of lubricating fluid (Four ball method). 